\title{
Artífices de la reforma exterior del monasterio toledano de Santa Fe a finales del siglo XVIII
}

\section{The artists of the exterior reform of the monastery of Santa Fe in Toledo at the end of the 18th century}

\author{
Jesús Ángel Sánchez Rivera \\ Universidad Complutense de Madrid
}

Fecha de recepción: 21 de mayo de 2017

Fecha de aceptación: 22 de junio de 2018

\author{
Anuario del Departamento de Historia y Teoría del Arte \\ vol. 29-30, 2017-2018, pp. 191-208 \\ ISSN: 1130-5517, eISSN: 2530-3562
}

http://doi.org/10.15366/anuario2017-2018.29-30.08

\begin{abstract}
RESUMEN
Se presenta documentación inédita que permite conocer por primera vez cuándo se acometió la reforma de las dos portadas exteriores del monasterio de Santa Fe de Toledo -antaño perteneciente a las Comendadoras de Santiago y hoy incorporado al complejo del Museo de Santa Cruz-y saber quiénes intervinieron en la misma. Asimismo, se analizan ambas realizaciones (portadas de la iglesia y de la portería) en el contexto histórico-artístico de su tiempo, haciendo especial hincapié en la actividad de sus artífices. Entre ellos, destaca la participación de José Antonio Vinacer, escultor de origen tirolés que trabajó en el ámbito toledano del último cuarto del siglo XVIII.
\end{abstract}

\section{PALABRAS CLAVE}

Monasterio de Santa Fe, Toledo. Siglo XVIII. Arquitectura. Escultura. José Antonio Vinacer.

\begin{abstract}
We present an unpublished documentation which allows to know when was made the reform of the two main fronts of the monastery of Santa Fe de Toledo -that was belonging to Comendadoras of Santiago and today is incorporated into the Museo de Santa Cruzand know who intervened therein. We also analyze both works (main front of the church and of the monastery) in the historical and artistic context of his time, with particular emphasis on the activity of its artists. Among them, stands out the participation of José Antonio Vinacer, sculptor from the Tirol who worked in Toledo in the last quarter of the eighteenth century.
\end{abstract}

\section{KEY WORDS}

Monastery of Santa Fe, Toledo. 18th century. Architecture. Sculpture. José Antonio Vinacer.

A Francisco J. Portela Sandoval

In memoriam

Hace apenas un lustro asistimos al fin de las obras de restauración y rehabilitación del conjunto que un día conformó el antiguo monasterio de Santa Fe el Real -o la Real, como refieren algunos documentos- de Toledo, que, de este modo, pasó definitivamente a ser integrado en el Museo de Santa Cruz tras años de abandono. 
Conocida es la fundación de aquel monasterio femenino de la Orden de Santiago a comienzos del siglo XVI, concretamente en 1505, aunque las monjas ya estaban establecidas en Toledo tres años antes, gracias al favor y a la protección dispensados por los Reyes Católicos. Con el paso de los siglos, y tras diversos avatares históricos, las órdenes militares españolas -entre ellas, la ínclita Orden santiaguista- fueron perdiendo el importante papel social que antaño habían desempeñado, y con él sus privilegios y su pujanza económica. Los cenobios femeninos de las mismas se vieron gravemente afectados, aun cuando intentaron mantener, a veces a duras penas, aquel prestigio aristocrático dentro del clero. La situación económica de la comunidad de freilas santiaguistas al comenzar el siglo XIX era realmente mala, y derivaba hacia una mayor precariedad conforme avanzaba la centuria, hasta que a fines del siglo XIX devino en una situación agónica. De este modo, en 1935, la mermada comunidad que por entonces habitaba el lugar tuvo que abandonar el monasterio para trasladarse a una parte de las dependencias de Santo Domingo el Real, donde aún hoy existe una comunidad santiaguista.

En el presente trabajo damos a conocer una serie de noticias de índole histórico-artística sobre obras que se llevaron a cabo en el edificio durante el último cuarto del siglo XVIII, notables ejemplos de la que, a nuestro juicio, constituye la última etapa de esplendor de este monasterio, que se cierra al terminar la centuria, unas décadas antes de su irremediable decadencia. Responde así a una serie de cuestiones hasta ahora desconocidas: ¿qué artífices intervinieron en la reforma de las portadas exteriores de la referida iglesia santiaguista? ¿Qué miembros de la Orden de Santiago realizaron y supervisaron el encargo? ¿Cuándo y cómo se desarrolló su proceso constructivo y decorativo? ¿Qué papel desempeñó en el panorama artístico toledano? ¿Existen conexiones con otras realizaciones nacionales o foráneas?

El hallazgo y transcripción de una serie documentos de carácter inédito, con el debido cotejo de otras fuentes primarias y secundarias, además del estudio de las propias obras - desde el punto de vista técnico, estilístico, socio-cultural e iconográfico- sustentan la metodología empleada y el resultado final. Con ello esperamos contribuir al conocimiento de esta singular fundación toledana, en otro tiempo pujante e insigne.

\section{Las dos portadas exteriores del monasterio: análisis y autoría ${ }^{1}$}

En las publicaciones que se han ocupado, con mayor o menor amplitud, del antiguo monasterio de Santa Fe no hemos encontrado ninguna aportación significativa sobre las dos portadas del edificio, que aún se conservan. Es más, se ha venido repitiendo, sin ningún fundamento, que el medallón "marmóreo" (?) que luce la portada de la calle de las Armas procedía del antiguo hospital de Santiago de los Caballeros, demolido en $1884^{2}$. Además, no se conocía la autoría de esta obra ni del otro medallón que, con el mismo asun-

1 El presente artículo se inscribe en el marco del proyecto de investigación titulado "Los escultores en la Corte durante el reinado de Carlos IV: sus obras y clientes, aspectos sociológicos, culturales y artísticos” (ref. PR26/16-20345; IP: Dra. María Teresa Cruz Yábar) de la Fundación Santander en convenio con la Universidad Complutense de Madrid (UCM), y constituye una pequeña parte de un estudio mucho más amplio sobre el patrimonio histórico-artístico de las Comendadoras de Santiago establecidas en Toledo. Algunos aspectos del mismo ya fueron dados a conocer en mayo de 2013, dentro del "V Encuentro Complutense: Jóvenes Investigadores de Historia del Arte", organizado por el Departamento de Historia del Arte II (Moderno) de la Facultad de Geografía e Historia de la UCM. Durante nuestra investigación resultaron de gran ayuda las orientaciones y noticias sobre el Palacio Real de Aranjuez que, con suma generosidad, nos ofrecieron los Drs. Francisco José Portela Sandoval (†), Javier Jordán de Urríes y María Jesús Herrero Sanz. Así mismo, expresamos nuestro agradecimiento al Dr. Juan Nicolau Castro, quien nos facilitó la monografía italiana sobre la familia Vinacer.

2 Julio Porres Martín-Cleto, La desamortización del siglo XIX en Toledo, Toledo, IPIET, 2001 ( $2^{\mathrm{a}}$ edición; $1^{\mathrm{a}}$ edición: 1965), pp. 154 y 340, nota 84. Tal vez la confusión vino tras leer la descripción de Parro de la portada del hospital santiaguista, donde cita "un medallón de mármol en que se representa en dicho relieve á Santiago á caballo matando moros, que no parece mala escultura” (PARro, Sixto Ramón, Toledo en la mano, tomo II, Toledo, 1857, p. 386), o a una mala lectura de las informaciones de Manuel Castaños y MontiJano, "El hospital de Santiago", Toledo. Revista de arte, IX (1923), pp. 613-614. Repite el error María Inés Melero Fernández, "El Hospital de Santiago de Toledo a fines del siglo XV", Anales toledanos, IX (1974), p. 30. De la 
to, luce la portada del antiguo monasterio situada en la calle de Santa Fe. A la luz de la documentación encontrada podemos precisar las fechas de ejecución de ambas obras, así como los artífices que intervinieron y las cantidades que se les pagaron.

Según certifican los documentos, entre 1789 y 1790 se acometieron diversas reformas en el exterior de la iglesia y el monasterio, además de la intervención en varias casas pertenecientes a la comunidad ${ }^{3}$. En los años precedentes se venían efectuando obras en el interior del templo (p. ej., los altares marmóreos de Eugenio López Durango y Juan Manuel Manzano), que continuaron con obras menores en los sucesivos, además de finalizar algunos remates exteriores ${ }^{4}$.

\section{Portada de la iglesia}

Algunos autores aseguran que la antigua portada de la iglesia, con acceso directo desde la calle de las Armas, ha de ser la que hoy se encuentra en uno de los extremos de la calle de Santa Fe, objeto de análisis en el siguiente epígrafe ${ }^{5}$; de ser cierto, el traslado desde su ubicación primigenia a la actual seguramente se produciría con las reformas acometidas en el siglo XVIII. Por otro lado, no sabemos qué motivó la construcción de la nueva portada, aunque, presumiblemente, pudiera haberse debido a un mal estado del acceso al templo y/o a motivaciones de carácter estético.

La granítica portada que ha llegado hasta nuestros días se compone a la manera de un retablo de un solo cuerpo con un gran ático, y se presenta superpuesta, como una segunda piel, a la construcción de ladrillo y mampostería (?) enlucidos. Así, el gran vano de ingreso queda enmarcado por una puerta adintelada de sillares almohadillados con faja en la parte exterior -cuya medida es $1 / 3$ del relieve almoha-

antigua portada del edificio, incluido el relieve que la adornaba, dejaron un testimonio más detallado el Comendador de Villarrubia y el licenciado Alonso de Cerecedo, visitadores de la Orden de Santiago que efectuaron la visita del 13 de julio de 1603: “[El hospital de Santiago] que está cerca del Alcázar y Casa Real, en la cuesta, a la parte oriental tiene la puerta y quarto delantero, al setentrión delante una plaza suya cercada la pared de cal y canto y en medio de la entrada una cruz grande de piedra berroqueña, y desde ella a la puerta tiene la dicha plaza setenta y quatro pies y al través ciento y sesenta y quatro pies, y la portada del dicho ospital de tres piezas grandes de la dicha piedra con las columnas y otras molduras que le dan buena gracia, encima della la ymagen del señor Santiago a caballo, dorada en partes de una piedra franca blanca e sobre ésta una bentana con una rreja de hierro muy grande con un escudo del ábito de Santiago; toda la demás delantera es de cal y canto con rrafas de ladrillo y su gallería con bentanaje en toda ella con diez y seis rrejas grandes medianas y pequeñas de hierro; las puertas son de madera de pino gruesas y muy bien labradas con unas beneras y ábitos de Santiago de hierro por clabazón (...)”. Archivo Histórico Nacional [en adelante AHN], Órdenes Militares, libro 7 (sin foliar); resaltamos en cursiva la información sobre el relieve. El testimonio escrito de la visita que se realizó en abril de 1537 al hospital toledano nos lleva a fechar la escultura y el resto de la portada en las primeras décadas del siglo XVI, acaso entre las décadas de 1520 y 1530 : "la portada es de jambas e colunas e lintel de piedra berroqueña y los capiteles y candeleros y arcos y entablamento y el bulto de Santiago a caballo es de piedra blanca, lo qual todo está muy bien dorado y nuevamente fecho (...)". AHN, Órdenes Militares, Uclés, libro 1083c; publicado por Eduardo JIMÉNEZ RAYADO, Santiago MuRIEL HernándeZ e Ignacio SÁncheZ Ayuso, Libros de visita de la Orden Militar de Santiago. Provincia de Toledo. Siglos XV-XVI, vol. II, Madrid, Almudayna, 2012, cita de la p. 159. Adviértase la descripción que se hace del repertorio decorativo y de los materiales; los elementos con una decoración más menuda (capiteles, candeleros y escultura de Santiago) eran de una piedra blanca, que sería más adecuada para ser esculpida con detalle que el granito. Inevitablemente, pensamos en los puntos en común -estructurales y decorativos- que podría tener con la cercana portada del hospital de Santa Cruz, construido por voluntad del cardenal Mendoza (1428-1495). Y, en relación con ello, añadiremos que las fotografías antiguas del desaparecido hospital de Santiago revelan que aquella primitiva portada se hubo de eliminar en el siglo XVIII, sustituyéndose por una estructura de dos pisos con vanos adintelados, el superior con balcón, y un ático decorado; sobre la entrada había un gran escudo de armas y en el centro del ático figuraba, nuevamente, un Santiago matamoros en un tondo. Demolido el hospital en 1884, esta portada dieciochesca se reutilizó en las nuevas dependencias de la Academia de Infantería, construidas sobre el solar anterior, edificios que, finalmente, fueron destruidos en 1936 durante los bombardeos de la Guerra Civil.

3 Archivo de las Comendadoras de Santiago de Toledo [en adelante ACST], Libro de Cuentas del Convento de Señoras Cavalleras de Santa Fe... (1788-1798), fols. 49-50. Vid. Apéndice documental. Documentación que se complementa con la contendida en el ACST, Libro de data del Real Monasterio de religiosas de Santa Fe que dio principio el año de 1783 , fols. 175 v.-176.

${ }^{4}$ Por falta de espacio, de estos encargos nos ocuparemos en otra ocasión. 


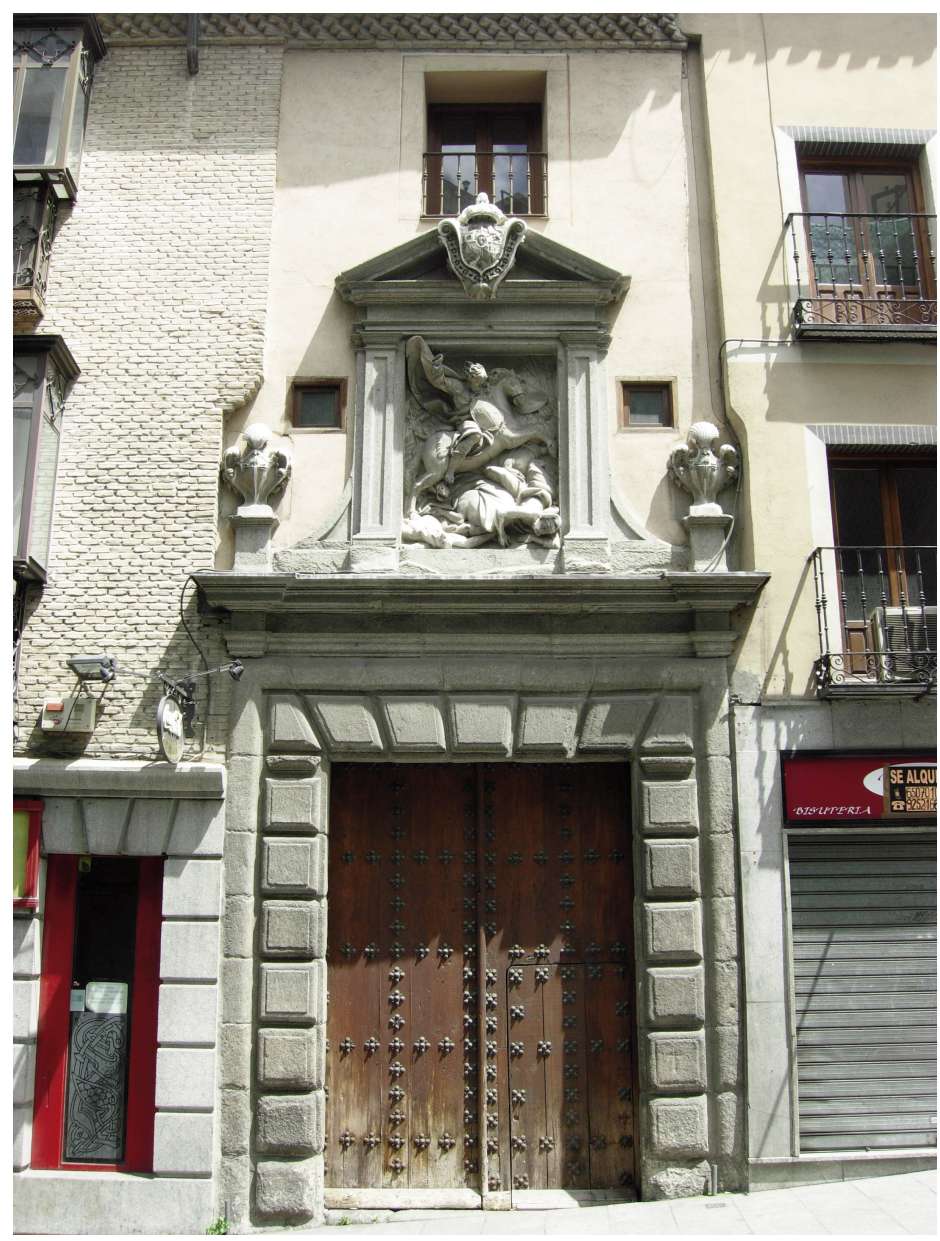

Fig. 1. Portada de la antigua iglesia del monasterio de Santa Fe, en la calle de las Armas de Toledo. dillado-; notable labor de cantería que ha sufrido deterioros, sobre todo en la parte inferior. Un entablamento, únicamente articulado mediante diversas molduras, da paso al ático, verdadero protagonista del conjunto por sus elementos escultóricos. Sobre aquél, se erigen sendos escudos santiaguistas sobre pedestales, en correspondencia con los salientes del entablamento. En el centro, y flanqueado por pequeños aletones, el ático, compuesto por pilastras cajeadas de capitel dórico, entablamento y frontón triangular con el escudo real en su vértice, amén del relieve central de Santiago que más adelante analizaremos (fig. 1) ${ }^{6}$.

En la ejecución de esta portada intervino Francisco Ximénez, maestro albañil, al que se pagaron 23.412 reales y 1 maravedí por dicha labor y por su trabajo en una casa aneja a la puerta de la iglesia, también perteneciente a las religiosas ${ }^{7}$. La carpintería corrió a cargo de Esteban Mazarrín, que recibió 11.291 reales por el trabajo y por la compra del material ${ }^{8}$. Asimismo, durante estas intervenciones se realizaron diversas obras de cerrajería, clavazón y vidriería, tanto en el convento como en las casas pertenecientes a él ${ }^{9}$.

Más difícil resulta determinar, por el momento, la autoría de las trazas de esta obra arquitectónica. En toda la estructura, armoniosa y proporcionada, quizá pueda vislumbrarse el magisterio o la huella rectora de la Real Academia de Bellas Artes de San Fernando, institución que, desde la Villa y Corte, veló por la

5 VV. AA., Arquitecturas de Toledo. Del periodo romano al gótico, vol. 1, Toledo, Junta de Comunidades de Castilla-La Mancha, 1992, p. 175 (ficha de Clara Delgado Valero). Julio Porres cita el Memorial de algunas cosas notables que tiene la Imperial Ciudad de Toledo, redactado por Luis Hurtado de Toledo en 1576, en el que se refiere: "[las Comendadoras] an abierto agora una puerta a la yglesia a la calle de las armas"; Julio PORRES MARTín-CLETO, Historia de las calles de Toledo, tomo I, Toledo, Zocodover, 1988, p. 202 (citamos por la $3^{\mathrm{a}}$ edición; $1^{\mathrm{a}}$ edición: 1971). Probablemente fuera esta portada del siglo XVI la que aún existiera antes de la reforma de fines del XVIII.

${ }^{6}$ Descrita brevemente por Vizconde de Palazuelos, Toledo. Guía artístico-práctica, Toledo, Menor y hermanos, $1890, \mathrm{p}$. 1079. También en VV. AA., 1992, p. 175.

7 Ximénez venía trabajando ininterrumpidamente para las Comendadoras al menos desde 1783, ocupándose en las reformas de las numerosas casas propiedad de las religiosas, haciendo el trastejo del monasterio, etc. ACST, Libro de data del Real Monasterio de religiosas de Santa Fe que dio principio el año de 1783, fols. 173-176. Uno de los pagos refiere el abono a Ximénez de 4.890 reales y 16 maravedíes para los canteros que labraron las piedras de la iglesia, cantidad contenida en el total de 23.412 reales y 1 maravedí que se entregaron al albañil entre abril de 1789 y diciembre de 1790; Ibidem, fol. $176 \mathrm{r}$.

${ }^{8}$ Documentamos diversos pagos de la comunidad santiaguista a Mazarrín en los años precedentes, en 1781, $1784-1786$ y 1788; Ibidem, fols. $173-176 \mathrm{r}$.

9 Vid. Apéndice documental, fols. 49-50. 
difusión del buen gusto que preconizaba en aquel último tercio del siglo XVIII ${ }^{10}$. Entonces, el lenguaje arquitectónico era sometido a un riguroso proceso de decantación formal, de acuerdo a los principios neoclásicos que se habían extendido por Europa.

Los tres escudos que coronan la portada fueron realizados por Juan Hernández, "adornista de cosas de talla", cuya actividad aparece documentada en Toledo durante la década de $1790^{11}$. El documento que cita el recibo de pago, del 5 de febrero de 1790, ha de leerse con cautela, pues erróneamente cita "los tres escudos (...) para las puertas de la iglesia y portería" aunque, como sabemos, aquéllos sólo se refieren a los ejecutados para la portada del templo. Las piedras habían sido trasladadas un mes antes desde Colmenar de Oreja por Luis Girado, vecino de esta villa, junto con otras dos más grandes para tallar los relieves. No sería la única vez que Girado transportase materiales para las fábricas toledanas; en 1801 se documentan diferentes pagos por el transporte de piedras marmóreas desde Lanjarón (Granada) con destino a la fábrica de los tres retablos que Ignacio Haan (c. 1756-1810) trazara en 1798 para la sacristía de la catedral ${ }^{12}$.

El escudo central que preside la fachada, sobrepuesto al frontón triangular del ático, corresponde al modelo abreviado de la Monarquía española, creado a la llegada al trono de Felipe V (1700-1746), y profusamente utilizado por Carlos III (1759-1788), Carlos IV (1788-1808) -tal como muestra este temprano ejemplar-, y sus herederos: cuartelado de Castilla y León con el escusón de Anjou en abismo y entado en punta de Granada; al timbre, Corona Real de España, y acolado a su alrededor, el Collar de la insigne Orden del Toisón de Oro. Su presencia en esta iglesia se debe al patronazgo que ejercieron los monarcas hispanos en la fundación de Santa Fe "la Real" desde los Reyes Católicos - de hecho, fueron aquellos reyes quienes favorecieron el traslado de la comunidad de monjas desde tierras palentinas- ${ }^{13}$; una presencia que encuentra mayor justificación, si cabe, ante la conversión de los reyes en administradores perpetuos de las órdenes militares peninsulares, precisamente desde el gobierno de Isabel y Fernando.

La tipología del escudo corresponde al gusto del momento, donde las formas tradicionales en el ámbito hispánico (de punta redondeada en U) se han estilizado de tal modo que el modelo resultante parece un híbrido entre aquél, el de punta amigdaloide y el modelo tarja -que tanta fortuna halló durante el pleno Barroco-. Sus perfiles curvos, con largas volutas laterales, evocan aún el gusto por las retorcidas formas barrocas, si bien atemperadas por una rigurosa simetría, propia ya de lo neoclásico.

Los dos escudos laterales lucen la cruz santiaguista, según el diseño que se fraguó durante el siglo XVIII -más estilizado que el heredado de la Edad Media, es el que finalmente se impuso y ha pervivido hasta la actualidad-; al timbre, sendas veneras alusivas igualmente a la Orden.

Juan Hernández demuestra en estas las piezas su excelente labor como tallista, haciendo gala de una fina y cuidadosa ejecución ${ }^{14}$. Buen hacer que también desplegaría en el trabajo de la madera, como queda patente en su intervención en el órgano neoclásico del coro de la catedral toledana (1791-1794), en la capilla Mozárabe (1797) -ambas con participación de Mariano Salvatierra (c. 1753-c. 1805), quien se ocupó de las figuras-y en el mobiliario de la nueva biblioteca catedralicia $(1798)^{15}$.

Más nos interesa ahora el estudio de los "medallones" que adornan las dos portadas mencionadas. Ambos se deben al escultor José Antonio Vinacer y Xiroer (1749-c. 1804). Y se ha de establecer su eje-

\footnotetext{
10 Nos ocupamos de la posible autoría de las trazas y de su filiación con la arquitectura del momento al analizar la otra portada.

11 Juan Nicolau CASTRO, Escultura toledana del siglo XVIII, Toledo, IPIET, 1991, pp. 185-186, 201.

12 Ibidem, pp. 132 y 188.

13 Ofrecemos una sintética explicación en Jesús Ángel SÁnCHEz RivERA, “Configuración de una iconografía singular: la venerable doña Sancha Alfonso, comendadora de Santiago", Anales de Historia del Arte, 18 (2008), p. 169.

14 Tal vez huelgue decir que la elección de la piedra de Colmenar, tanto para los escudos como para las esculturas de Santiago, se debe a que ésta permite un trabajo más fino que la piedra berroqueña con que está construida el resto de la fachada -y había de ser más barata que el mármol-. Con el empleo de ambos materiales, granito gris y piedra blanca, se logra una bicromía característica -sin fijarnos en el paramento enlucido-, presente en muchísimas construcciones de este período.

15 Nicolau Castro, 1991, pp. 185-186 y 201.
} 


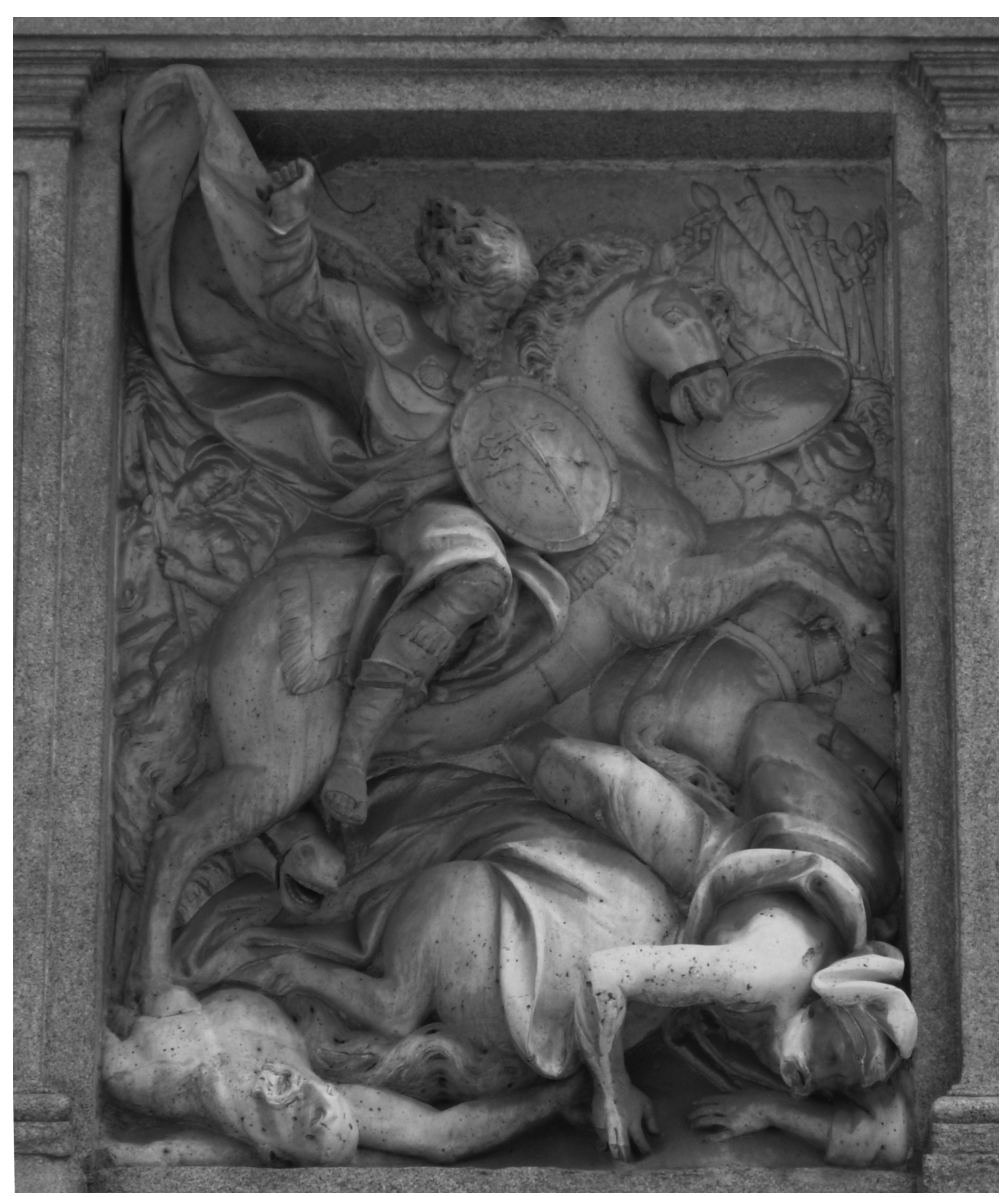

Fig. 2. José Antonio Vinacer, Santiago en la batalla de Clavijo, 1790, relieve en piedra blanca de Colmenar con adornos de hierro, iglesia del monasterio de Santa Fe, Toledo.

El atuendo característico de Santiago aúna su doble condición de apóstol (manto adornado con veneras, túnica larga, calzón y borceguíes, es decir, prácticamente transmutado con el tiempo en un peregrino) y de miles Christi, correspondiente al asunto representado (caballero con espada y escudo con la cruz santiaguista). La acometida del santo, empuñando la espada a lomos de un caballo encabritado, se traduce en sus largos cabellos en movimiento y el amplio vuelo de su manto; no así en su rostro, que desprende gran serenidad y nobleza, acordes con su santidad. Los musulmanes mueren bajo las patas del caballo, caen de sus caballerías o huyen despavoridos; todo es espanto y caos, en contraste con la enérgica templanza del santo. Los infieles están caracterizados a la manera tradicional (con la cabeza afeitada o turbante, bigotes y un escudo con la media luna). En un segundo plano, al lado derecho se atisban banderas y lanzas musulmanas en retirada, y a nuestra izquierda un caballero cristiano enarbolando una bandera en señal de victoria (fig. 2).

En nuestra opinión, resultaría ocioso tratar de encontrar una filiación directa de esta composición con un precedente en concreto. Nos inclinamos por la hipótesis de que el artista se pudiera inspirar en una o varias obras, ya fueran estampadas, pintadas o esculpidas -acaso alguna que poseyeran las monjas santiaguistas-, para crear a una composición propia que, por otra parte, se ajusta a la tradición iconográfica de este asunto. No obstante, sí queremos apuntar que el tipo de escudo empuñado por el santo es similar al que aparece en un grabado de la época abierto por Manuel Salvador Carmona (1734-1820), coincidencia que no deja de ser meramente anecdótica. 
A pesar de las reducidas dimensiones del soporte y de su ubicación en altura, este trabajo brindó al escultor la ocasión de mostrar sus dotes para la representación de una historia sagrada -hoy diríamos legendariatan enraizada en nuestra cultura visual. Una escena que le permitiría cincelar figuras humanas en diversas posturas y actitudes (en un despliegue de escorzos y expresiones dramáticas), animales enardecidos, tejidos en movimiento, etc. Incluso, Vinacer trató de representar el espacio a través de una talla en diferentes planos, desde el altorrelieve de Santiago y los dos moros caídos hasta el bajorrelieve de las figuras del segundo plano; como resultado, el deseo de introducir tal número de figuras visibles desde la calle en un espacio tan reducido se traduce en un efecto de horror vacui con ciertas incorrecciones de perspectiva.

Las líneas compositivas principales se definen idealmente sobre los ejes de dos diagonales: una diagonal ascendente trazada por el caballo de Santiago y otra diagonal, que se cruza, definida por el otro caba1lo -sólo visible en sus cuartos traseros- y continuada por el manto del santo, único elemento que se sale ligeramente del marco arquitectónico. En esta composición subyace un preciso estudio geométrico, con las dos diagonales trazadas en el marco rectangular que se cruzan en el centro del cuerpo del caballo y dividiendo el espacio en cuatro triángulos, iguales dos a dos. Ante el espacio reducido del que disponía y lo abigarrado de la escena, el escultor optaría por una solución ordenada, aunque no exenta de dinamismo, graduando el relieve para fingir la profundidad. Este modo compositivo bien pudiera relacionarse con el influjo de las enseñanzas académicas del momento, aunque, a nuestro entender, en él destaca, sobre todo, el peso del espíritu tardobarroco, muy patente aún en buena parte de la producción de Vinacer, al igual que en la de otros escultores españoles de su época.

Por otra parte, el grupo armado, así como los escudos de la Orden, resultan muy convenientes para el emplazamiento al que iban destinados, pues la obra se encuentra en la calle de las Armas, así denominada al menos desde el siglo XV en virtud de los oficios allí localizados. Ésta conforma el tramo final de una de las principales vías de entrada a la antigua ciudad de Toledo y, desde luego, la de pendiente más suave desde la Vega ${ }^{16}$. Es, por esta razón, un espacio especialmente representativo. En este sentido, quizá no se deban pasar por alto las connotaciones históricas del asunto elegido, por muy vagas y remotas que fueran ya a fines del siglo XVIII: el convento santiaguista se alzaba sobre el antiguo emplazamiento de los palacios musulmanes de la Galiana. Además, y esto es más importante, en ella se encuentra la entrada al templo santiaguista, siempre de mayor importancia que el acceso a una portería, según la jerarquía arquitectónica del Clasicismo. En consecuencia, se reservó el otro relieve, de menor empaque, para la entrada secundaria de la calle de Santa Fe, que en realidad es un callejón sin salida, al final del cual está la portada referida, aunque con una interesante perspectiva visual antes de penetrar a la ciudad por el Arco de la Sangre.

\section{Portada de la portería}

La segunda portada sobre la que se intervino a fines del siglo XVIII fue la que cierra la calle de Santa $\mathrm{Fe}$, acceso a la portería del antiguo monasterio. Responde a un modelo propio de la segunda mitad del siglo XVI -aunque se continuó haciendo en las primeras décadas del XVII- del que podemos encontrar algunos ejemplos todavía conservados en Toledo. Se compone de un arco de medio punto flanqueado por columnas adosadas de orden jónico romano sobre altos pedestales. El arco, trasdosado y sobre impostas molduradas, luce una ménsula en la clave y una venera en cada enjuta. El friso se decora con una cadena de cuadrados y óvalos alternos ${ }^{17}$; arquitrabe y cornisa presentan molduras; dos escudos santiaguistas (cruz de la

\footnotetext{
16 Lo explica ampliamente Porres Martín-Cleto, 1988, tomo I, pp. 201-204.

17 Se ha pensado que su origen estaría en la decoración de aplicaciones de bronce que lucían algunas piezas de mobiliario, simulada más tarde en otros soportes como la cerámica, el grabado, etc. Por ejemplo, en el interior de la iglesia santiaguista, concretamente en el arco de la primera capilla del lado de la Epístola, podemos contemplar una decoración análoga realizada con molduras de estuco.
} 


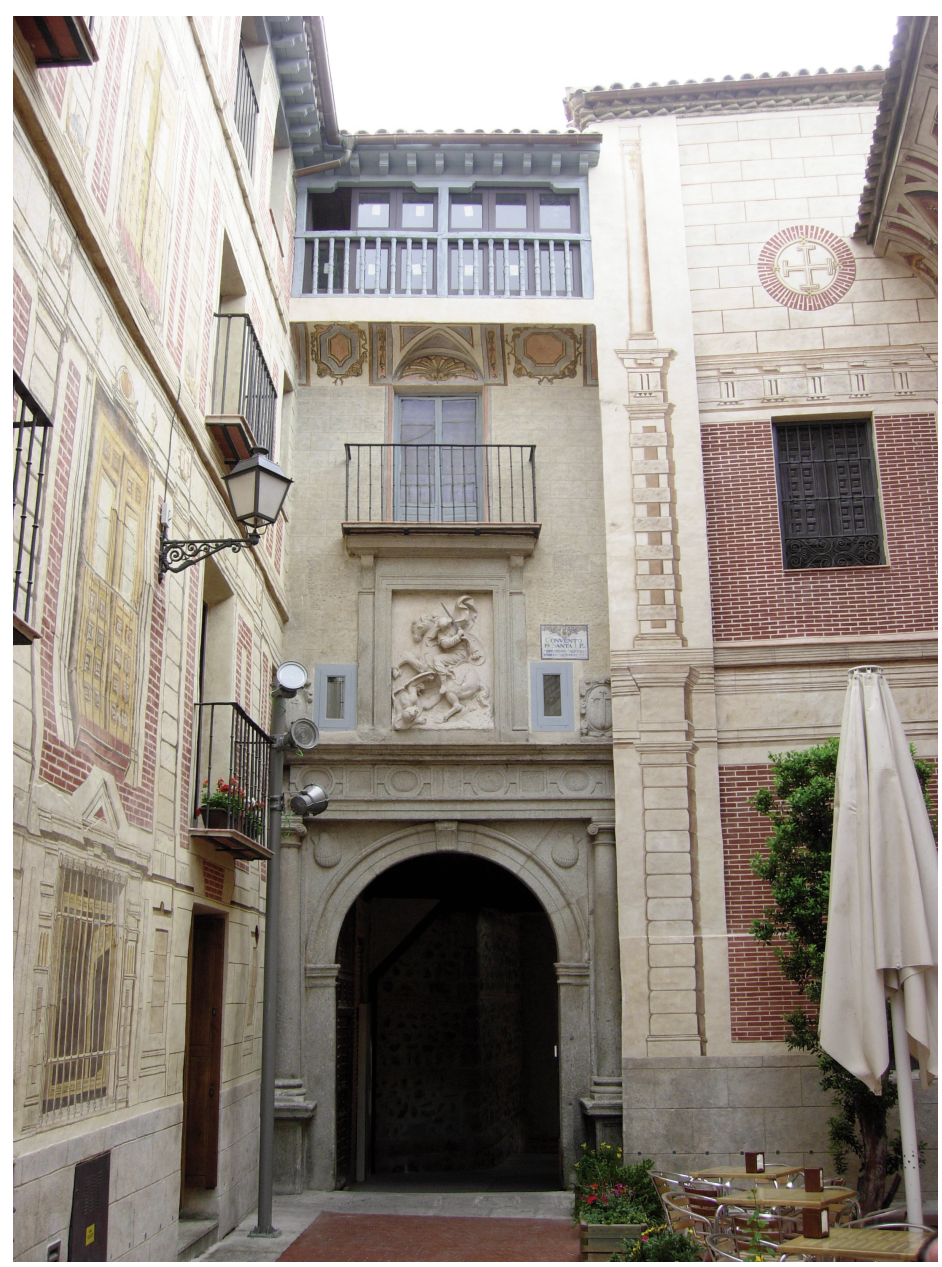

Fig. 3. Portada de la portería del monasterio de Santa Fe, en la calle de Santa Fe de Toledo.
Orden sobre espejos ovales y marco imitando cueros recortados) coronan cada extremo del entablamento (fig. 3).

Ya se ha explicado que, en opinión de algunos estudiosos, esta estructura conformaba la antigua portada de la iglesia, lo que parece coincidir con su probable cronología. Asimismo, su presentación, torpemente encajada entre las casas, apoyaría la hipótesis de un traslado desde aquella ubicación. Porres señaló que hasta fines del siglo XVII o principios del siglo XVIII la calle de Santa Fe permaneció abierta en uno de sus extremos hasta el espacio delimitado por el conjunto santiaguista y el hospital de Santa Cruz, y sólo entonces fue cerrada, privatizando esta zona por medio de la portería de las Comendadoras ${ }^{18}$; sin embargo, las descripciones halladas en los libros de visita de la Orden de Santiago nos llevan a considerar que aquella apertura era parcial, pues, al parecer, la calle ya se clausuraba por las noches desde principios del siglo $\mathrm{XVI}^{19}$. Las viviendas que rodean este acceso (por los flancos y en altura, por medio de un cobertizo) están decoradas con pinturas murales de motivos arquitectónicos fingidos, recientemente restau$\operatorname{rados}^{20}$, y en una de ellas figura repetida

18 Porres Martín-Cleto, 1988, tomo III, p. 1289.

19 En la primera visita conservada tras la creación del monasterio toledano, efectuada en abril de 1537, se lee: "Los dichos visitadores visitaron dicho monesterio y començaron la visitación desde una puerta que sale a la calle, que se dice la puerta de Santiago el Mayor, la qual puerta se çierra cada noche y tiene cargo de çerrar Juan Martínez, despensero, y junto a ella está la iglesia que nuevamente se a fecho (...)"; AHN, Órdenes Militares, Uclés, libro 1083c; publicado por JiMÉNEZ RAYADO, MURIEL HERNÁNDEZ y SÁNCHEZ AYUSO, 2012, vol. II, cita de la p. 107. También sería de interés localizar una copia de la visita que se realizó entre el 3 y el 14 de mayo de 1566, documento referido por Laura Canabal que no hemos podido localizar en el archivo de las Comendadoras, pues quizá podría aportar alguna información más al respecto; $c f r$. Laura CANABAL RodRíGUEZ, "La Orden Militar de Santiago en Toledo. Una visita al convento de Santa Fe en 1566", en Jerónimo LóPEz-SALAZAR PÉrez (coord.), Las órdenes militares en la Península Ibérica. Vol. II: Edad Moderna, Cuenca, Universidad de Castilla-La Mancha, 2000, pp. 2279-2291.

${ }^{20}$ Una antigua fotografía en blanco y negro que conservan las religiosas de Santiago revela que la restauración ha falseado alguno de estos motivos pintados, por hallarse prácticamente perdidos en el momento de la intervención; por ejemplo, la gran cruz de la parte superior del cierre de la calle - cita del hospital fundado por el cardenal Mendoza- estaba enmarcada por una suerte de ático de diseño barroco, no sólo por el círculo de ladrillos fingidos que hoy luce. Otra fotografía de Mariano Moreno García muestra los dos guardarruedas de granito pagados en 1789 al cantero José Angulo, hoy desaparecidos; vid. Apéndice documental, fols. 49-50. La hallamos en un álbum que localizamos en la antigua Colección de Luis Alba (Toledo), titulado "Información sobre el convento de «las Caballeras» de Toledo", firmado por don Benigno Vega, marqués de la Vega-Inclán, y fechado en septiembre de 1919, que contiene 30 fotografías del monasterio de Santa Fe positivadas en papel con la marca de "M. Moreno. Madrid"; sospechamos que el trabajo se realizó con motivo de la declaración del monasterio como Monumento Arquitectónico-Artístico el 30 de septiembre de ese año de 1919, declaración que se publicaría unos días después, el 8 de octubre. Aún se conserva en la referida 
la fecha de esta decoración: "AÑO DE 1747"; “AÑO DE MDCCXLVII". Estas inscripciones son un indicio más de las transformaciones que se realizaron en la calle a lo largo de aquella centuria, cuyo proceso está por aclarar.

Las puertas de madera se encargaron a Esteban Mazarrín, que también participó en la iglesia, y el coste de los jornales para su elaboración ascendió a 1.171 reales $^{21}$.

Por otra parte, se advierte a simple vista que el remate central de la portada, un marco moldurado con el medallón de Santiago matamoros, no se corresponde con la época en que se levantó aquélla ${ }^{22}$. Ahora podemos corroborar lo que salta a la vista, y demostrar documentalmente que el relieve se debe también a Vinacer.

Ante el encargo de dos relieves con el mismo asunto, Vinacer, en lugar de idear composiciones similares, buscó la variación, comenzando por la misma posición de las figuras, que en este caso se presentan en sentido inverso; es decir, Santiago acomete a su enemigo desde el lado diestro hacia el izquierdo. El santo de nuevo empuña la espada con la mano derecha, atacando con firmeza, lo que obliga a un forzado contrapposto de su cuerpo, que revela un atento estudio del movimiento anatómico. Ahora no se ve el frente de los

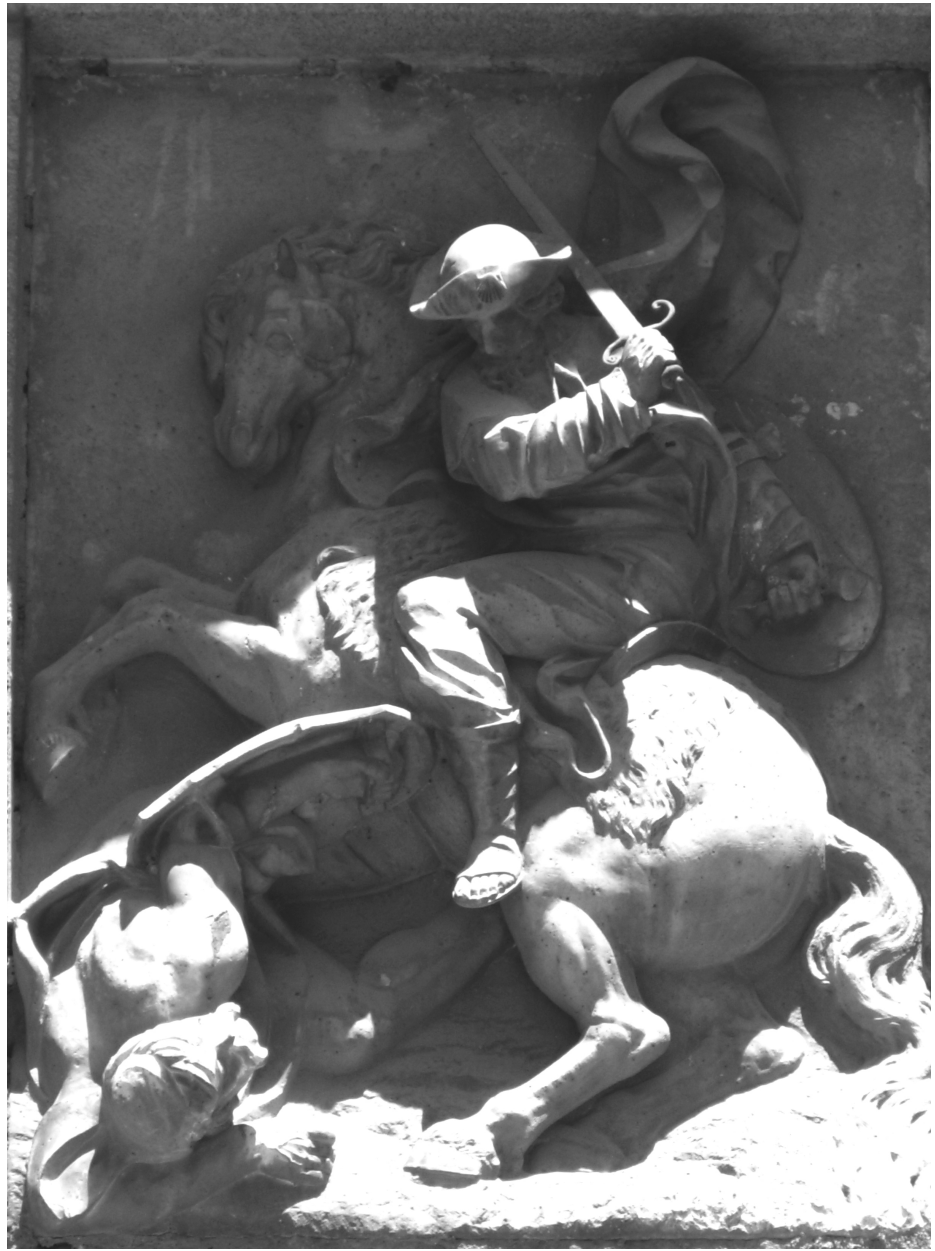

Fig. 4. José Antonio Vinacer, Santiago en la batalla de Clavijo, 1790, relieve en piedra blanca de Colmenar con adornos de hierro, portería del monasterio de Santa Fe, Toledo.

escudos sino el reverso (con las abrazaderas o enarmas), ni aparecen los soldados del segundo plano, que se resuelve de un modo neutro, sin buscar la profundidad más allá de las tres figuras representadas (Santiago, el caballo y el moro). Existen otras pequeñas variaciones respecto al primer relieve: el santo cubre su cabeza con un sombrero de ala ancha con venera; la montura ofrece un trabajo mayor, toda ella imita mechones de lana o piel; y el caballo dobla más las patas, como en corveta, mientras que el anterior parecía saltar por encima de los infieles. En este caso Santiago sí conserva íntegra su espada; no así las bridas del caballo (fig. 4).

Sin embargo, en este trabajo subyace de nuevo la articulación de la escena sobre dos diagonales compositivas que se cruzan en el centro del rectángulo, solución a la que recurrió el artista para ordenar las figuras, que, otra vez, ofrecen un dinamismo propio del Barroco tardío.

fachada una placa de azulejos de la fábrica talaverana de Ruiz de Luna que señala dicha distinción, colocada en virtud de una Real Orden comunicada a las Comendadoras el 6 de noviembre de 1924 por la Comisión de Monumentos Históricos y Artísticos de la Provincia de Toledo.

21 ACST, Libro de data del Real Monasterio de religiosas de Santa Fe que dio principio el año de 1783, fol. $176 \mathrm{r}$.

22 Ya pareció advertir esta circunstancia PAlazUelos, 1890, p. 1074, y fue señalada en VV. AA., 1992, vol. 1, p. 175. 
En otro orden de cosas, se ha de apuntar que, tal vez, la repetición del mismo asunto jacobeo para esta portada puede resultar algo extraña. A nuestro juicio, quizá parecería más adecuada -o decorosa- la elección de un Santiago peregrino para el acceso a la portería. Y, siguiendo este argumento, cabe plantearse -a modo de hipótesis casi imposible de verificar- si la insistencia en la representación bélica pudo estar motivada por la idea de evocar las gestas cristianas de la Reconquista, vinculándola de manera simbólica a este espacio emblemático de la ciudad recuperada por Alfonso VI (1047-1109), según habíamos señalado.

Por los dos medallones el escultor cobraría 11.000 reales, a los que han de añadirse 470 reales con los que, dos semanas más tarde, la Comendadora Mayor $^{23}$ les gratificó a él y a su oficial ${ }^{24}$. En nuestra opinión, estas cantidades revelan la buena consideración que se tenía de su trabajo en Toledo.

Por último, queremos volver a la segunda portada, y más concretamente al marco del relieve, que sirve, a su vez, de balcón en su parte superior. Dicho marco, rectangular y de molduras rectas, está flanqueado por dos pilastrillas; y su parte superior, a modo de arquitrabe, da paso a un "friso" liso y a una cornisa moldurada sobre sendas ménsulas. Este diseño, de enorme severidad, permite situarlo en el contexto de la reforma que venimos estudiando. Probablemente, su traza delata el influjo de arquitectos académicos como Ignacio Haan, arquitecto del Arzobispado de Toledo desde 1787, a quien bien pudiera deberse ${ }^{25}$, o a alguno de los maestros de su entorno. La comparación con las ventanas del edificio de la universidad de Santa Catalina de Toledo -fábrica en la que participó Vinacer-, proyecto de Haan realizado unos años después, resulta esclarecedora. La documentación únicamente revela, sin embargo, la participación de Francisco Ximénez como ejecutor de esta pequeña intervención y de la portada de la iglesia. Ximénez era maestro de albañilería de la ciudad de Toledo y alarife jurado de su Ayuntamiento, y por entonces participaba como tasador de las casas que se habían de comprar para la construcción del hospital del Nuncio Nuevo ${ }^{26}$, además de intervenir en diversas fases de la construcción del cercano muro del Miradero ${ }^{27}$. En definitiva,

23 A la sazón, doña Isabel Ma Treviño Carvajal. Había ingresado en Santa Fe en 1734, profesando seis años más tarde. Sus hermanas doña Juana $\mathrm{M}^{\mathrm{a}} \mathrm{y}$ doña Beatriz $\mathrm{M}^{\mathrm{a}}$ también fueron religiosas del monasterio. Ocupó el cargo de Subcomendadora y de Comendadora Mayor en varias ocasiones. Falleció en 1797.

${ }^{24}$ Compárese con los 32.000 reales que cobró por entonces Mariano Salvatierra por realizar ocho estatuas, también de piedra de Colmenar y algo menores del natural, para la capilla de Santiago de la catedral, a razón de 4.000 reales cada una; vid. NiCOLAU CAstro, 1991, p. 184. Por otro lado, el documento revela la existencia de un oficial, aunque no refiere su nombre; en consecuencia, hemos de pensar en que Vinacer tuviera un taller con una o varias personas a su cargo cuya identidad está por descubrir.

${ }^{25}$ La relación entre Francisco Ximénez e Ignacio Haan se certifica en diversas actuaciones durante la década de 1790; por ejemplo, recordemos que desde 1794 Ximénez estuvo a las órdenes de Haan como sobreestante de la Catedral. Para Haan, remitimos a la reciente monografía de Adolfo de Mingo, Ignacio Haan. Arquitecto de la luz, Madrid, Consorcio de la Ciudad de Toledo, 2010; en sus páginas aparecen diversos artífices documentados en la intervención de las Comendadoras que trabajaron junto al arquitecto alicantino en varias ocasiones (Francisco Ximénez, Luis Girado, José Antonio Vinacer, José Cano, Antonio Rojo o Esteban Mazarracín). Añadiremos, como curiosidad, que Haan había sido discípulo de Francesco Sabatini (1721-1797), quien ya había participado en la remodelación de dos monasterios de la Orden entre 1774 y 1779: Santiago el Mayor (Madrid) y la Madre de Dios (Granada).

26 Vid. Carlos SÁnchez Martín, "Estudio y documentación del proceso constructivo del Hospital de Dementes del Nuncio Nuevo de Toledo (1788-1794)", en La Iglesia Española y las Instituciones de Caridad. Actas del Simposium, Madrid, Instituto Escurialense de Investigaciones Histórico-Artísticas, 2006, pp. 677-680; Mercedes Alonso Morales, "Hospital del Nuncio Nuevo (1790-1836)", Anales Toledanos, XLIII (2007), pp. 223-227.

27 Manuel Gutiérrez GarcíA-Brazales, "El paseo del Miradero", Anales toledanos, VIII (1973), pp. 53-85. A fines de 1784 se derrumbó el viejo muro existente en la subida a Zocodover; de este modo, el Ayuntamiento de la ciudad acordó que Francisco Ximénez reconociera las ruinas junto a los comisarios del cuartel de Alcántara y Puerta Nueva (informe del 14 de enero de 1785). Una semana más tarde, Ximénez presentó su proyecto de acondicionamiento y reforma del nuevo Miradero (aprobado el 24 de enero), con un presupuesto de 19.300 reales. En agosto de 1785 ya se había reconstruido el muro, restando el acondicionamiento del espacio superior. Al parecer, al año siguiente el cardenal Lorenzana se comprometió a costear parte de la obra, entrando a participar en ella el maestro alarife Pedro Antonio Sigler (o Sirler) y Eugenio López Durango, maestro mayor de la ciudad. La obra se concluyó en mayo de 1789, pero poco después, el 13 de julio, se vino abajo parte del muro, matando a un arriero con sus caballerías. Tras el suceso, el oficial de cantero José Angulo declaró que, mientras estaba haciendo una roza -bien trabajando para las Comendadoras, bien en la obra del Miradero-, había oído y visto cómo se partían los ladrillos. Junto a otros alarifes de la ciudad, Francisco Ximénez intervino en el reconocimiento del murallón y, una vez determinado que se debía derribar y reconstruir la fábrica, fue apuntalado por Esteban Mazarrazín -otro nombre asociado a la obra de las Comendadoras- y derribado por Ximénez; 
no queda claro aún quién dio las trazas para las estudiadas remodelaciones. Acaso fuera Haan o alguno de los de su círculo más próximo, la obra que Ximénez ejecutó para las Comendadoras demuestra la permeabilidad del gusto neoclásico propugnado por la Real Academia madrileña en aquel Toledo finisecular.

Llegados a este punto, y a modo de colofón, quisiéramos señalar la importancia de poner en relación estas intervenciones con las reformas auspiciadas bajo el gobierno del cardenal Francisco Antonio de Lorenzana y Buitrón (1722-1804). El prelado impulsó una renovación edilicia y urbanística en la ciudad del Tajo (el citado hospital del Nuncio Nuevo, la universidad de Santa Catalina o la Puerta Llana de la catedral de Toledo, entre otras empresas), que también irradiaría y cristalizaría en multitud de obras en templos de la vasta Archidiócesis toledana.

\section{Algunas notas más sobre la obra del escultor José Antonio Vinacer}

Vinacer había nacido en abril de 1749 en el caserío tirolés de Bleje di Roncadizza, en el seno de una familia de escultores que hunde sus raíces en la primera mitad del Seiscientos ${ }^{28}$. Probablemente sería en el taller de su padre, Mattia, donde se iniciara en el oficio, aunque también hubo de ejercer como comerciante, abandonando la casa familiar. Se desconoce aún su formación fuera de este entorno y el motivo de su venida a España. Sin embargo, ya en nuestro país, declaraba orgulloso ser discípulo del escultor y académico Juan Pascual de Mena (1707-1784) ${ }^{29}$; al no haber hallado su nombre entre los asistentes a la Real Academia en las décadas de 1770 y 1780, creemos poder afirmar que trabajaría en el taller del toledano sin pasar por las clases de dicha institución, pues ya dominaría el oficio cuando arribara en España.

En Toledo se relacionó con Eugenio López Durango (1729-1794), y en la madrileña Real Academia de San Fernando con Manuel Álvarez (1721-1797), Mariano Salvador Maella (1739-1819) e Ignacio Haan ${ }^{30}$; todos ellos, como es sabido, realizaron obras para la catedral, además de intervenir en varios templos dependientes de la Sede toledana. La participación de Vinacer en obras ideadas por López Durango, frecuentemente en colaboración con el marmolista Juan Manzano, está documentada desde 1785; y, precisamente, los tres maestros trabajaron en fechas muy cercanas para las Comendadoras. A lo largo de la década de 1790, otra figura vinculada laboralmente al escultor tirolés fue Ignacio Haan, relación que convendría estudiar más en profundidad ${ }^{31}$.

Las primeras piezas documentadas con certeza de Vinacer son las esculturas que hizo para el retablo mayor de la iglesia parroquial de Almorox (Toledo), cuando el artista contaba con unos 36 años, es

esta intervención fue costeada por el propio Cardenal, quien expresó su deseo de prescindir de Sigler y López Durango para la tarea a favor de Ximénez. La reconstrucción definitiva del paredón tuvo lugar entre abril de 1792 y noviembre del año siguiente, interviniendo los ya citados Sigler y López Durango, el cantero Martín Marichalar y el rejero Antonio Rojo -acaso emparentado con Marcelino Rojo, citado entre los pagos de las monjas por diversas labores de cerrajería entre 1789 y 1790 -

28 Para esta saga, véase la monografía de Nicolò RASMO, Gli scultori Vinazer. Origini dell attività scultorea in Val Gardena. In appendice Giuseppe Antonio Vinacer di Juan Nicolau Castro, Toledo, Ortisei, Museo della Val Gardena, 1989; para José Antonio Vinacer, véanse las pp. 27 y 275-295.

29 Juan Nicolau Castro, "El escultor Juan Pascual de Mena", en Goya, 214 (1990), p. 204; Nicolau CASTro, 1991, p. 193. Sobre los discípulos de Pascual de Mena, Lorenzo Pérez Domingo, El escultor Juan Pascual de Mena en Madrid, Madrid, Fundación Universitaria Española, 2007, pp. 42-45.

30 Así lo expresaba el escultor ante la petición que hizo ante el cardenal Lorenzana para intervenir en el retablo mayor de la parroquia de La Guardia (Toledo): "ha acreditado en diferentes obras de piedra, estuco y madera, lo que consta en Toledo a don Eugenio López Durango y en Madrid a la Real Academia, y particularmente a don Manuel Álbarez, a don Mariano Maella y a don Ignacio Haan, arquitecto"; Archivo General de la Diócesis de Toledo [en adelante AGDT], Templos, TO 6, 29. Noticia publicada en su día por Nicolau CASTRo, 1991, pp. 130 y 193. Como vemos, Vinacer presentó su solicitud refiriendo los nombres de cuatro artistas conocidos por el Cardenal, quienes por entonces, además, ostentaban importantes cargos, tanto en la Sede toledana como en la Academia madrileña.

31 Ibidem, ad indicem. 
decir, en plena madurez ${ }^{32}$. El gesto triunfal de la Asunción de la Virgen recuerda lo que se venía haciendo desde el ámbito madrileño -con resonancias del Barroco italiano-, y más concretamente algunas obras de Juan Pascual de Mena, como el desaparecido San Isidro de la colegiata madrileña de San Isidro el Real, y de alguno de sus seguidores, como Fernando del Cid (doc. 1753-1779) ${ }^{33}$. También se conserva el medallón que remata el retablo, representando a San Cristóbal con el Niño Jesús sobre los hombros. El modelo iconográfico para esta figura hay que buscarlo, en última instancia, en el prototipo creado por Alberto Durero (1471-1528), del cual se hicieron innumerables copias y versiones durante los siglos posteriores, como la que ahora comentamos, modesto epígono modernizado de madera, imitando un relieve marmóreo. No se han conservado las dos esculturas de tamaño natural que flanqueaban a la Virgen, entre las columnas -posiblemente ángeles o virtudes-, ni los dos ángeles con una guirnalda de rosas.

Por otro lado, tras revisar la documentación relativa a la construcción del retablo mayor de la iglesia de La Guardia (Toledo) creemos oportuno replantearse la participación de nuestro escultor en él. Nicolau le asignó la Adoración del nombre hebreo de Yahvé por ángeles realizada en estuco para remate del conjunto, por aparecer su nombre entre aquellos papeles ${ }^{34}$. Sin embargo, este punto aún resulta algo dudoso, a tenor de los datos contenidos en los mismos legajos y de ciertos aspectos estilísticos, aunque postergaremos su estudio para otro momento, pues un análisis riguroso excedería los límites de estas páginas. Avanzaremos, no obstante, que dicho remate se hubo de acometer durante los primeros meses de 1791, en fecha muy cercana a las obras analizadas de las Comendadoras de Santiago.

En relación con los dos relieves que hizo para las Comendadoras, se han de señalar las semejanzas técnicas y formales con la estatua de San Agustín que realizara en piedra de Colmenar para la fachada del desaparecido convento de los Agustinos Recoletos de Toledo, hoy conservada en el Museo de Santa Cruz de la misma ciudad ( ${ }^{\circ}$ inv. 141). Las fisonomías de los tres santos son muy similares, de gestos nobles y atemperados; también resultan semejantes el modo de inclinar la cabeza hacia abajo -adecuándose a la ubicación en altura de cada fachada- y la forma sintética de resolver los paños.

Es posible que Vinacer estuviera en Roma antes de recalar en España, pues se puede percibir el influjo de aquella ciudad en algunas de sus realizaciones, como ya señalara Nicolau Castro. El imponente escudo que corona la fachada principal de la Universidad de Santa Catalina se ha puesto en relación con la heráldica romana, sobre todo por la figura de la fama trompetera, que parece derivar de las que ideara Bernini (1598-1680) y ejecutara Ercole Ferrata (1610-1686) para el escudo de Alejandro VII (1599-1667) en la Scala Regia del Vaticano ${ }^{35}$. La referida Gloria que corona el retablo de La Guardia (Toledo) -de autoría dudosa- y, sobre todo, los Ángeles adoradores del monasterio de San Clemente evocan modelos berninescos. No obstante, nuestro escultor también pudo tener presente otros referentes más cercanos, sin necesidad de recurrir directamente a los prototipos originarios; recordemos, por ejemplo, el escudo de armas rea-

32 Ibidem, pp. 193 y 196. No obstante, hay que señalar que Ramírez de Arellano dio noticia de un contrato de obligación del escultor, de 7 de julio de 1784, en que se obligaba a "hacer una grada y sagrario para el altar mayor de la parroquia de S. Vicente, por 800 reales, y le anticiparon la mitad”, acabándosele de pagar el 16 de enero de 1785; Rafael RAMíREZ DE ARELLANO, Catálogo de los artífices de Toledo, Toledo, IPIET, 2002 ( $1^{\text {a }}$ edición de: Toledo, 1920), p. 326. Noticia que no fue recogida por Nicolau y que no hemos podido comprobar personalmente, aunque la precisión de los datos aportados nos lleva a confiar en su fiabilidad. De este modo, ésta sería la primera obra conocida de Vinacer en Toledo, unos meses antes de su intervención en Almorox.

33 Cfr. Pérez De Domingo, 2007, pp. 174-176, fig. 67; María Teresa Cruz YÁBAR, “El escultor Manuel Álvarez (1721-1797)”, vol. I, Tesis Doctoral, Madrid, Universidad Complutense de Madrid, 2003, pp. 80-81, 287-290; Jesús Ángel SÁNCHEZ RivERA, "El escultor Fernando del Cid. Algunos datos sobre su vida y su actividad artística”, en Archivo Español de Arte, LXXXIII, 331 (2010), pp. 249-266. Del retablo de San Isidro se conserva un bello dibujo en el Museo Nacional del Prado ( $\mathrm{n}^{\circ}$ cat. D003053), obra de Manuel Salvador Carmona, y otros dos en la Biblioteca Nacional de España (B. 1939 y B. 1940), además de antiguas fotografías realizadas antes de su destrucción en 1936.

34 Nicolau Castro, 1991, pp. 130 y 193.

35 Rudolf WitTKower, Gian Lorenzo Bernini, Madrid, Alianza, 1990, pp. 284-285, nº cat. 68 (1ª edición: Oxford, Phaidon, 1955). 
les flanqueado por dos famas que Roberto Michel (1720-1786) realizara para el edificio sabatiniano de la antigua Real Aduana de Madrid ${ }^{36}$.

También, y creemos que es una observación inédita hasta ahora -pese a que se especifica en el contrato de obligación- ${ }^{37}$, las parejas de ángeles eucarísticos de este monasterio siguen modelos romanos. El documento referido establece que estos ocho ángeles, agrupados en parejas, "serán concluidos parte por las obras admirables de los griegos -vaga referencia muy del gusto de entonces- y del famoso Flamenco". Estas últimas palabras aluden al bruselense François Duquesnoy (1597-1643), quien desarrolló su carrera de manera brillante en la Ciudad Eterna, donde era conocido como "il Fiammingo". Los putti y angelillos de este escultor tuvieron una enorme repercusión en el arte de su tiempo, y aún en la siguiente centuria, fenómeno que ya advirtiera Wittkower, exageradamente, con estas palabras: "Fue la concepción del bambino de Duquesnoy la que se convirtió en propiedad europea, y consciente o inconscientemente, la mayoría de las representaciones posteriores de niños pequeños se deben a él" 38 . Aunque en la monografía de Boudon-Machuel sobre el flamenco no aparece un modelo exactamente igual, sí creemos que, en general, los ángeles de Vinacer entroncan perfectamente con los prototipos de aquél, y así parece corroborarlo el angelillo que, de pie, sostendría algún instrumento, muy similar en su pose al Niño Jesús/Cupido que ideara Duquesnoy ${ }^{39}$.

Sin embargo, continuando con este asunto, se ha de advertir que al menos una de estas parejas de angelotes, la que porta un haz de espigas (fig. 5), deriva de un grupo marmóreo realizado por Domenico Guidi (1625-1701). El original, hoy desaparecido, al parecer representaba la imagen alegórica del Amor profano y el Amor sagrado, encarnados en sendos amorcillos pugnando por una hoja de palma, con un carcaj lleno de flechas y lazos a los pies ${ }^{40}$. Fue un encargo de la reina Cristina de Suecia a Guidi para su palacio en Roma y, décadas después de haber fallecido la soberana, fue adquirido por Felipe V en 1724, llevándose al Palacio de San Ildefonso (Segovia) con otras piezas. En 1791 la obra fue trasladada al Palacio Real de Aranjuez, donde aún queda recuerdo de su presencia a través de los grupos de putti de la puerta de la verja que cierra la cour $d$ 'honneur del Palacio -el que sostiene un haz de espigas, en el pedestal derecho- ${ }^{41}$; son piezas modernas que, sin duda, copian o se inspiran en otras antiguas repartidas por los jardines en el siglo $\mathrm{XVIII}^{42}$. Entre aquella fecha de 1791 y 1799 se realizó un vaciado de yeso del grupo -intervalo en el que

36 Vid. Francisco Sabatini, 1721-1797. La arquitectura como metáfora del poder, Delfín Rodríguez Ruiz (comis.), Madrid, Electa (catálogo de la exposición celebrada entre octubre y diciembre de 1993), 1993, pp. 182-184 (texto de Francisco José Portela Sandoval).

37 Archivo Histórico Provincial de Toledo [AHPT], José Covos, P-1002, fols. 234-235. Documento dado a conocer por Nicolau, quien ya señaló su carácter excepcional; NiCOLAU CASTRO, 1991, pp. 194 y 391-392.

38 Rudolf WitTKOwer, Arte y Arquitectura en Italia, 1600-1750, Madrid, Cátedra, 1999, p. 276 (1ª edición: Harmondsworth, Middlesex, Penguin Books, 1958).

39 Cfr. Marion Boudon-Machuel, François Duquesnoy, 1597-1643, París, Arthena, 2005, pp. 73 y 325, figs. 71 y 72 , cat. In. 116 , ex.1, ex.2 y ex.3.

40 Cristiano Giacometti, Domenico Guidi, 1625-1701. Uno scultore barocco di fama europea, Roma, "L'Erma" di Bretschneider, 2010, pp. 348-349.

41 El grupo que corona el lado contrario sostiene racimos de uvas, aunque en este caso no sigue el mismo prototipo que los ángeles con racimos del monasterio toledano; sin embargo, recuerdan de nuevo los niños de Duquesnoy. Por otra parte, casi parece obvio apuntar que estas esculturas pretenden representar, de algún modo, la fertilidad de la vega de Aranjuez; y acaso se pudiera buscar una segunda lectura en clave alegórica, en relación con la abundancia auspiciada por los monarcas españoles.

42 Parece ser que hacia 1974 se terminaron unas obras en el Palacio encaminadas a su acondicionamiento como residencia para los Jefes de Estado extranjeros. Por entonces se realizaría la verja actual bajo la dirección del arquitecto Ramón Andrada, recuerdo de la que hubiera cerrado las alas proyectadas por Sabatini; al parecer, la verja, también concebida por el arquitecto palermitano, nunca se levantó, aunque sí fue representada hacia 1773 en el grabado de Manuel Salvador Carmona dibujado por Francisco de Aguirre. La representación de este proyecto frustrado ya desaparece en la obra de Fernando Brambilla litografiada por Asselineau, fechada en 1823, que forma parte de la Colección de las Vistas del Real Palacio de Aranjuez, dirigida por José de Madrazo. Cfr. El Real Sitio de Aranjuez y el Arte Cortesano del Siglo XVIII, Araceli Pereda Alonso (comis.), Madrid, Patrimonio Nacional (catálogo de la exposición celebrada entre abril a mayo de 1987), 1987, pp. 321, $\mathrm{n}^{\mathrm{o}} 17,322, \mathrm{n}^{\circ} 20,324, \mathrm{n}^{\circ} 25$ y $327, \mathrm{n}^{\circ}$ 34; Francisco Sabatini, 1721-1797..., Delfín Rodríguez Ruiz (comis.), 1993, pp. 126, 129-138. Según se ha dicho, los grupos escultóricos de la puerta son de factura moderna, realizados en el taller de los hermanos Béjar, pero haciendo juego con otros que 


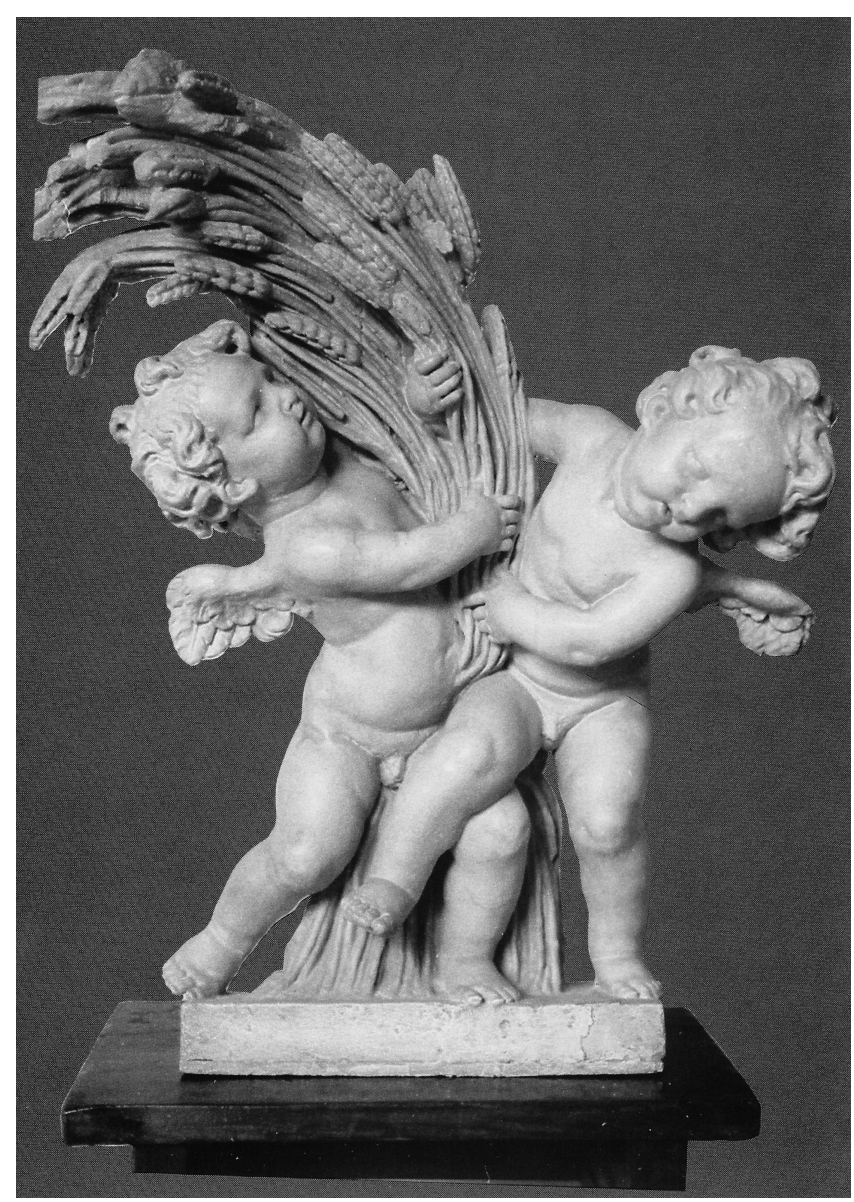

Fig. 5. José Antonio Vinacer, Ángeles eucarísticos, 17941795 , madera tallada y pintada de blanco, monasterio de San Clemente, Toledo. se inserta el encargo del Monasterio de San Clemente a Vinacer, de 1794-, que hoy aún se conserva en el Patio de la Fuente del Palacio de San Ildefonso. Y, en fecha imprecisa, su última localización conocida estuvo en el madrileño Parque de El Retiro ${ }^{43}$.

Esta "trasmutación" de un asunto pagano a otro sagrado -o viceversa- pone de relieve la versatilidad de estos modelos de bambini creados por el escultor flamenco y por otros artistas del ambiente romano seguidores de la estela de Bernini, como Guidi, y su enorme repercusión en el arte posterior ${ }^{44}$.

Por cierto, el contrato de obligación aludido desvela la manera de trabajar del artista -al menos en este caso-, combinando el estudio de ciertas estatuas clásicas (Antinoo y Apolo) ${ }^{45}$, del natural (de "un Joven vivo" y de los ropajes) y de esculturas del Barroco clasicista ("del famoso Flamenco", es decir, Duquesnoy) ${ }^{46}$; un modo de proceder y una terminología que nos conduce, una vez más, a las enseñanzas académicas de su tiempo.

Las tres imágenes de madera policromada realizadas para el Calvario de la iglesia toledana de San Nicolás de Bari constituyen su obra más destacada, tanto por el tratamiento anatómico y gestual como por el trabajo de los ropajes. En esta obra tardía, el tirolés resolvería buena parte de las

hay en el Parterre y que están atribuidos a Juan Bautista Martínez Reyna (1728-1801), escultor de Caravaca (Murcia) formado en la Real Academia de San Fernando que trabajó mucho en el Real Sitio de Aranjuez, además de intervenir en las obras del Palacio Real de Madrid. Como refiere Ceán, fue nombrado académico de mérito de aquella institución en 1796. Juan Agustín CEÁN BERMúDEZ, Diccionario histórico de los más ilustres profesores de las Bellas Artes en España, tomo III, Madrid, Viuda de Ibarra, 1800, p. 94.

43 De esta última ubicación es, al parecer, una antigua fotografía en blanco y negro del grupo marmóreo (fig. 6), que generosamente nos ha facilitado D. Javier Jordán de Urríes.

44 No es extraño, por lo tanto, que las obras de Duquesnoy fuesen copiadas contemporáneamente por los alumnos de la Academia madrileña pensionados en Roma, como es el caso de Isidro Carnicero (1736-1804), de quien se conservan una copia en barro cocido de la magistral Santa Susana (iglesia de Santa María de Loreto). Carnicero envió otras terracotas, muestra de su aprendizaje romano: copia del Antinoo capitolino, de la Tumba de Gregorio XIII (San Pedro del Vaticano) y del San Mateo de San Juan de Letrán, ambos de Camillo Rusconi (1658-1728), de una Inmaculada del círculo de Pierre Puget (1620-1694), del célebre grupo del Laocoonte y de la Santa Bibiana de Bernini; vid. Leticia Azcue BreA, La escultura en la Real Academia de Bellas Artes de San Fernando. Catálogo y Estudio, Madrid, Real Academia de Bellas Artes de San Fernando, 1994, pp. 187-197. Con muy buen criterio, Carnicero copió la Santa Susana de Duquesnoy y la Santa Bibiana de Bernini, obras que, pasados los siglos, serían comparadas por Wittkower con gran agudeza para ejemplificar "dos enfoques distintos: el Barroco y el Clásico"; WITTKOWER, 1999 , p. 274.

45 La primera puede que se sea el Antinoo del Vaticano, estatua admirada por el círculo clasicista romano (Algardi, Duquesnoy, Poussin, Bellori) y por el mismo Bernini; vid. Ibidem, p. 61. En cuanto a la segunda, posiblemente se trate del célebre Apolo del Belvedere, igualmente admirado por aquellos.

46 Los Ángeles adoradores de San Clemente derivan, indiscutiblemente, de los ejecutados por Bernini entre 1673-1674 para la capilla del Sacramento de la basílica de San Pedro del Vaticano, como bien advirtiera Nicolau. Hay que matizar y precisar, por 
incorrecciones que observamos en las primeras tallas que hasta ahora conocemos de su mano ${ }^{47}$.

A través de estos breves apuntes a la obra de Vinacer, finalmente, queremos llamar la atención sobre un escultor que tuvo una importancia singular en Toledo, aunque su labor se viera justamente ensombrecida por otros artífices españoles que gozaron del favor del cardenal Lorenzana (p. ej., López Durango y Salvatierra). Sobre él surgen aún numerosas incógnitas en torno a su formación italiana, a su presencia en Madrid y a varias obras que se le atribuyen. Deseamos y confiamos que todas estas incógnitas se vayan despejando en el futuro.

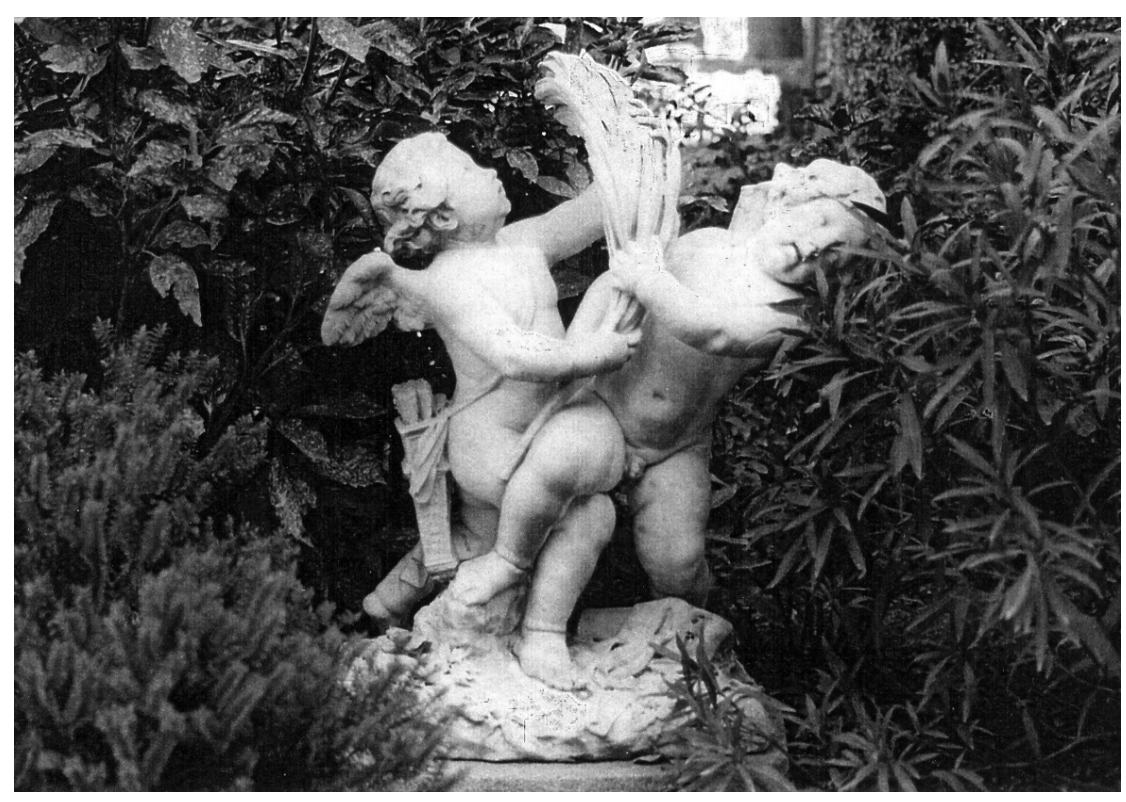

Fig. 6. Domenico Guidi (atrib.), Amor profano y Amor sagrado (?), 1686, antiguamente en el Parque del Retiro, Madrid (por cortesía de D. Javier Jordán de Urríes).

\section{Conclusiones}

A través del presente trabajo, fundamentado sobre documentos inéditos, se han podido despejar diversos interrogantes existentes en torno a la reforma de las dos portadas monumentales de acceso al antiguo monasterio de Santa Fe. En primer lugar, el conocimiento de la autoría de los dos relieves que presiden ambas portadas, obra de José Antonio Vinacer, y su cronología precisa. De esta manera, queda aclarada definitivamente la confusión entre una de las portadas referidas y la que existió en el antiguo hospital de Santiago, desaparecido en el último cuarto del siglo XIX. Asimismo, se ofrecen datos desconocidos para el estudio de esta última realización, complementando así investigaciones precedentes.

Junto a Vinacer, en la intervención participaron otros artífices para acometer diversas labores constructivas, escultóricas o de otra índole. De todos ellos damos cuenta, poniéndolos en relación con la actividad constructiva desarrollada en Toledo durante el último tercio del siglo XVIII.

A través de los pagos registrados en el libro de cuentas del monasterio, podemos conocer las cantidades de dinero desembolsadas a cada uno de los artífices entre 1789 y 1791, pudiendo confrontarlas con otros encargos documentados de la época. La reforma se produjo durante la prelatura de doña Isabel $\mathrm{M}^{\mathrm{a}}$ Treviño Carvajal, quien desempeñaría un relevante papel como Comendadora Mayor del monasterio en las últimas décadas de aquel siglo.

lo tanto, una parte de las condiciones a las que Vinacer se comprometió en el contrato de estas imágenes, al menos en que lo se refiere a sus fuentes iconográficas. Sin embargo, el recuerdo de los modelos infantiles de Duquesnoy, "il Fiammingo", en las parejas eucarísticas que Vinacer realizara para San Clemente nos parece bastante claro, aunque también se les podría aplicar la apreciación de Nicolau, quien dijo de ellas: “participan más del espíritu rococó que del neoclásico y parecen salidos de la decoración de un jardín de un palacete"; Nicolau CASTRO, 1991, p. 197. De hecho, la presencia en el Palacio Real de Aranjuez de modelos similares apoyaría dicha apreciación.

47 Vid. Nicolau Castro, 1991, pp. 195-196 y 197-198; Rasmo, 1989, figs. 231-232. 
Se ha prestado especial atención en contextualizar la reforma de la iglesia santiaguista en el ambiente histórico-artístico de Toledo. En este sentido, la obra de las Comendadoras viene a sumarse a la Renovatio urbis auspiciada por el cardenal Lorenzana. Las empresas urbanísticas y artísticas que tuvieron lugar durante su gobierno en la ciudad, entre 1772 y 1800, suponen una particular plasmación de los ideales de la Ilustración española; una interpretación en clave conservadora, muy arraigada en la tradición local, pero también con múltiples -y lógicas- conexiones con el ambiente cortesano de Madrid.

Finalmente, aportamos ciertas noticas y apreciaciones, algunas formuladas a modo de hipótesis, en relación con la obra del escultor José Antonio Vinacer. Su formación italiana, su paso por la Corte madrileña o su actividad en la Archidiócesis de Toledo aún constituyen una vía de investigación poco explorada. 


\section{Apéndice documental}

\section{Pagos por diversas obras en el Monasterio y en sus casas (ACST, Libro de cuentas del Convento de Señoras Cavalleras de Santa Fe..., 1788-1798, fols. 49-50, 68 v.-69 v.).}

“[Fols. 49-50] No 36. Obras y reparos en el Convento y sus casas.

Del mismo modo se le pasan en data cinquenta y seis mil quatrocientos dos reales y diez maravedíes vellón pagados a Francisco Ximénez, Estevan Mazarrazín, Josef Cano, Ventura Moreldos, Francisco Rubio y otros vecinos de esta dicha ciudad por el importe de las obras que cada uno respectivamente ha executado en el expresado Real Convento, sus casas, hazienda de la Alberquilla y coste de las dos medallas grandes colocadas sobre las puertas de la yglesia // y portería, con el Santo Patrón, escudos y armas, desde el 18 de abril de 1789 hasta fin de diciembre de 1790, a saver:

Por 4 recivos de Francisco Ximénez, maestro de albañilería, desde 18 de abril de 1789 hasta 3 de septiembre de 1790. Obra de albañilería executada en dicho Real convento y la casa inmediata a la puerta de la yglesia..... 23.412 [reales], 1 [maravedí].

Por cuenta y recibo de Antolín Pintado, obra echa en la Alberquilla en el año de 1787 1.032 [reales], 16 [maravedíes].

Por cinco cartas cuentas y recivos de Estevan Mazarrazín, maestro de carpintería, de la obra executada en una casa, calle de las Armas, y en dicho Real Convento, incluso la madera comprada para ellas desde 6 de julio de 1789 hasta 5 de febrero de 1790 11.391 [reales].

Por recibo de Juan Hernández, de 5 de febrero de 1790, de hacer los tres escudos de piedra de Colmenar para las puertas de la yglesia y portería 1.500 [reales].

Por otro 18 de agosto de 89 de Josef Angulo, oficial cantero vecino de esta ciudad, por un batiente que hace 18 pies y dos guardaruedas, que cada uno hace 8 pies $1 / 2$ de piedra berroqueña, a 8 reales y $1 / 4$ cada pie. 358 [reales], 26 [maravedíes].

Por otro 7 de enero de 1790 de Luis Girado, vecino de Colmenar, por el porte y principal de las dos medallas grandes de piedra y de los tres escudos de armas colocados en dichas puertas. 2.453 [reales], 17 [maravedíes].

Por otro de Josef Antonio Vinacer y Xiroer, vecino de esta ciudad, por la construcción de dos medallas de piedra, Santiago a caballo, para las fachada (sic: fachadas) de la puerta de la yglesia y portería de dicho Real Convento. Fecha 13 de septiembre de 1790 11.000 [reales].

Por recibo de la señora Comendadora, de 27 de septiembre de 90, gratificación al escultor Josef Vinacer y su oficial por la construcción de dichas medallas. 470 [reales].

Por 4 cartas cuentas y recivos de Marcelino Roxo, Diego Arroyo y Josef Cano, de 20 de agosto, 6 de septiembre, 20 de diciembre de 1789 y 29 de diciembre de 1790. Obra de cerragería executada en el Convento y sus casas..... 2.527 [reales], 33 [maravedíes].

Por dos cartas cuentas de Francisco Rubio, // maestro de vidriero, de 21 de diciembre de 1789 y 29 de dicho de 1790. Obra executada en dicho Real Convento 1.120 [reales], 17 [maravedíes].

Por 4 cartas cuentas de Ventura Moreldos y Francisco Díaz, de 13 de octubre, 18 de noviembre de 1789, 20 de agosto y 29 de septiembre de 1790. Obra de clabazón entregada para las executadas en dicho Real Convento. 1.136 [reales], 2 [maravedíes].

Que dichas partidas componen los expresados cinquenta y seis mil quattrocientos dos reales y diez maravedíes vellón, como consta de dicho libro a los folios 176 buelto y 208, y de 25 recivos y cartas cuentas de los contenidos maestros que han executado las referidas obras, los que con el número 36 presenta para la justificación de esta partida..... 56.402 [reales], 10 [maravedíes]. 
[Fols. 68 v.-69 v.] № 38. Obras y reparos del combento y sus cassas.

Además se le reciven en datta quatro mil ciento quarenta y nuebe reales y veinte y siete maravedíes vellón pagados a los maestros de empedrador, albañilería, carpintería, dorador, ojalatería, clavero y cerraxero, vecinos de esta dicha ciudad, por el importe de las obras executadas por cada uno respectivamente en el dicho Real Combento y sus casas desde 1 de enero de 1791 hasta // 22 de mayo de éste de la fecha, a saber: (...)".

JESÚS ÁNGEL SÁNCHEZ RIVERA es Profesor Ayudante Doctor del Departamento de Didáctica de las Ciencias Sociales de la Universidad Complutense de Madrid. Su principal línea de investigación se ha centrado en el arte sacro de la Edad Moderna, en especial el perteneciente a la Orden de Santiago. Fruto de ello fue su Tesis Doctoral, publicada bajo el título: El Real Monasterio de Comendadoras de Santiago el Mayor de Madrid: patrimonio históricoartístico (2014). Es autor de varias decenas de artículos de investigación en revistas nacionales y extranjeras, en los que ha estudiado bienes inmuebles, cuestiones sociológicas e iconográficas, obras de escultores (José de Mora, Torcuato Ruiz del Peral, Juan Pascual de Mena, Luis Salvador Carmona o Roberto Michel), de pintores (Juan de Borgoña, Mateo Cerezo o Luca Giordano) y de platería madrileña, toledana y andaluza. Actualmente es miembro del proyecto I + D titulado "La herencia de los Reales Sitios: Madrid, de Corte a Capital (historia, patrimonio y turismo)" [CMM-COURT-TOURIST-CM, ref. S2015/HUM-3415"; Comunidad de Madrid/Fondo Social Europeo], y del proyecto de investigación "Los escultores en la Corte durante el reinado de Carlos IV: sus obras y clientes, aspectos sociológicos, culturales y artísticos” [ref. PR26/16-20345; Fundación Santander/UCM].

Email: jasanchezrivera@edu.ucm.es 